\title{
Asymmetry of the Foramen Rotundum and of the Foramen Ovale
}

\author{
Alexandre Mendes Luz, ${ }^{1}$ Matheus Barros Domingos, ${ }^{1}$ Gabriela Faria Reis Queiroz, ${ }^{1}$ João Vitor Pereira Cunha, ${ }^{1}$ Humberto Santo \\ Neto $^{2}$ \\ ${ }^{1}$ Faculty of Medicine, União das Faculdades dos Grandes Lagos, São José do Rio Preto, São Paulo, Brazil \\ ${ }^{2}$ Department of Structural and Functional Biology, Institute of Biology, Universidade Estadual de Campinas, Campinas, São Paulo, Brazil
}

Disclose and conflicts of interest: none to be declared by all authors

\begin{abstract}
Introduction: asymmetry of the foramen rotundum and of the foramen ovale has been singled out as a possible factor that contributes to the pathogenesis of trigeminal neuralgia - considering the affected side, the predominance of females affected, and the absence of a direct correlation with the classic presentation. The present morphometric study of the foramen rotundum and of the foramen ovale sought to assess the role of asymmetry and its incidence according to gender in the pathogenesis of primary trigeminal neuralgia.

Materials and Methods: a total of 104 human skulls of both genders were used to study the morphometry of the foramina, taking into account the side and gender of the samples. The tabulation of data and statistical analyses were performed using IBM SPSS Statistics for Windows, Version 21.0.

Results: statistically relevant variations were observed in the foramen diameters

between the right and left sides and the width of the right foramen rotundum, which

was smaller in female specimens.

Conclusions: there was asymmetry between the right and left sides of the skull, and the foramen rotundum was significantly smaller on the right side in females, which could explain the compressive neuropathy of the trigeminal nerve which develops in female patients.
\end{abstract}

Keywords: Anatomical variation; Foramen ovale; Foramen rotundum; Trigeminal neuralgia

\section{Introduction}

Trigeminal neuralgia (TN) is a type of neuropathy with an annual incidence of $\sim 4.5$ per 100,000 people, ${ }^{1,2}$ and it is characterized by an excruciating paroxysmal facial pain described as tic doloureux. ${ }^{3}$

The pathogenesis of most cases of $\mathrm{TN}$ is related to direct compression of the nerve as a result of an aberrant location of the superior cerebellar artery, which features a compressive syndrome in $67.5 \%$ of the cases $^{4}$ and, according to some authors, in $80 \%$ to $90 \%$ of the cases ${ }^{1}$-all of which may increase with age. Given the vascular pathogenesis theory of $\mathrm{TN}$, the transverse vein tip can be singled out as a possible contributing factor. ${ }^{5}$ Other causes, such as demyelination and familial origin, are classified as less frequent and even sporadic causes, including those attributed to cancers and hemodynamic disorders. ${ }^{1}$

However, some patients present with primary TN, in which the pathogenesis is still not fully understood. Some cases of neuropathymanifest a predominant incidence in the right side ${ }^{2,6,7}$ and are not explained by "classical" pathogenesis hypotheses.

The asymmetry of the foramen rotundum (FR) and the of the foramen ovale (FO) and the openings through which the maxillary (V2) and mandibular (V3) roots travel, have been known for some time, ${ }^{8}$ and it has been considered a possible causative factor of the painful presentation of neuralgia, taking into account the predominance of the affected side (right) and the absence of a direct correlationwith the causes described in the literature. ${ }^{9,10}$ Moreover, a predominance of this incidence in female patients and the progressive nature of this condition with age has been described. ${ }^{3,6,7}$

The relationship between the anatomy of the FR and of the FO with its vascular and nervous components should be taken into account when performing clinical and surgical procedures in this region, as it represents an important means of communication between the intracranial and extracranial compartments from the floor of the middle fossa. ${ }^{11-14}$

Given the controversy surrounding the relevance of these correlations, the present study assessed themorphometry of the FR and of the FO, taking into account their asymmetries and incidences according to gender, as a possiblemechanism for understanding of the pathogenesis of primary TN.

\section{Materials and Methods}

The present work was submitted to CEP Unicamp with theexemption of ethical assessment by CEP / PRP / No. 030/2017. A total of $104(n=104)$ dry human 
skullswere collected from the collection of anatomical specimens of the Human Anatomy Laboratory of the Department of Cellular and Structural Biology, Institute of Biology, Universidade Estadual de Campinas, Campinas, state of São Paulo, Brazil, and the Human Anatomy Laboratory of the Faculty of Medicine, União das Faculdades dos Grandes Lagos, São José do Rio Preto, state of São Paulo, Brazil. They were classified and divided according to gender (male, $\mathrm{n}^{1 / 486}$; and female, $\mathrm{n}^{1 / 418}$ ), in accordance with the anthropological identification criteria established by White et $a l .{ }^{15}$

The morphometric study of each skull was based on bilateral measurements of the length and width of the FR and of the FO of the skulls. ${ }^{10}$

Data tabulation and the statistical analyses of the present study were performed using IBM SPSS Statistics forWindows, Version 21.0 (IBM Corp.,
Armonk, NY, USA) with descriptive analyses forallvariables, and the Kolmogorov-Smirnov (KS) and Shapiro-Wilk normality tests. To compare several variables between the right and left sides, we used a generalized linear mixedmodel (GLMM) to control for the effect of gender. A $p$-value $<0.05$ was considered statistically significant. The effect sizeinterpretation,partial etasquared, established $0.01<\mathrm{n}^{2}<0.06=$ small effect; $0.06<\mathrm{n}^{2}<0.14=$ average effect and $0.14<\mathrm{n} 2=$ large effect. ${ }^{16-18}$

\section{Results}

The data obtained fromthemorphometry analysis of the left and right FR and FO are represented in Table 1. The results of the morphometric characteristics analysis for the correlationbetween the size of the foramen, side, and gender are shown in Table 2.

Table 1. General descriptive analysis of the measures of the foramen rotundum and the of the foramen ovale in $\mathrm{mm}$

\section{Foramen rotundum (FR) Foramen ovale (FO)}

Right Left Right Left

\begin{tabular}{l|c|c|c|c|c|c|c|c}
\hline & L & W & L & W & L & W & L & W \\
\hline Median & 3.0 & 3.0 & 3.0 & 3.0 & 7.0 & 3.0 & 7.0 & 4.0 \\
\hline Maximum & 4.0 & 4.0 & 4.0 & 4.0 & 11.0 & 7.0 & 12.0 & 8.0 \\
\hline Minimum & 1.0 & 1.0 & 2.0 & 1.0 & 4.0 & 2.0 & 4.0 & 1.0 \\
\hline Mean \pm SD & $2.8 \pm 0.6$ & $2.5 \pm 0.7$ & $2.8 \pm 0.6$ & $2.5 \pm 0.6$ & $6.9 \pm 1.3$ & $3.3 \pm 0.8$ & $6.8 \pm 1.3$ & $3.6 \pm 1.0$ \\
\hline
\end{tabular}

Abbreviations: L: length; SD, standard deviation; W: width.

Table 2. Generalized linear mixed model analysis. Morphometry of the gender rotundum and of the foramen ovale in $\mathrm{mm}$, given side and sex

\section{Foramen rotundum (FR) Foramen ovale (FO)}

Right Left Right Left

\begin{tabular}{l|c|c|c|c|c|c|c|c}
\hline Gender & $\mathbf{L}$ & $\mathbf{W}$ & $\mathbf{L}$ & $\mathbf{W}$ & $\mathbf{L}$ & $\mathbf{W}$ & $\mathbf{L}$ & $\mathbf{W}$ \\
\hline Female & $2.7 \pm 0.5$ & $2.2 \pm 0.6$ & $2.8 \pm 0.6$ & $2.5 \pm 0.5$ & $6.5 \pm 1.4$ & $3.0 \pm 0.9$ & $6.2 \pm 1.3$ & $3.4 \pm 1.0$ \\
\hline Male & $2.8 \pm 0.6$ & $2.6 \pm 0.7$ & $2.8 \pm 0.6$ & $2.5 \pm 0.6$ & $6.9 \pm 1.3$ & $3.4 \pm 0.8$ & $6.9 \pm 1.3$ & $3.6 \pm 0.9$ \\
\hline
\end{tabular}

Abbreviations: L: length; W: width. Bold: $p=0.030 ; \eta^{2}=0.046$.

Considering the analysis of the total sample, ignoring gender, a statistically significant variation was observed in the size of the diameters between the right and left sides of the FR and of the FO $\left(\mathrm{F}_{(4.99)}=3.478 ; p=0.011 ; \eta_{\mathrm{p}}{ }^{2}=0.123\right)$. No significant effect of gender on all variables was observed $\left(\mathrm{F}_{(4.99)}=1.969\right.$; $\left.\mathrm{p}=0.105 ; \eta_{\mathrm{p}}{ }^{2}=0.074\right)$.

Considering the analysis by variable, excluding gender, a statistically significant variation in the FO width was observed $\left(\mathrm{F}_{(1.102)}=8.303 ; p=0.005 ; \eta_{\mathrm{p}}\right.$ ${ }^{2}=0.075$ ), with the right side exhibiting a smaller mean diameter than the left side (Table 1).

A discrete trend of significant variation for the FR width $\left(\mathrm{F}_{(1.102)}=2.936 ; p=0.090 ; \quad \eta_{\mathrm{p}}{ }^{2}=0.028\right)$ was observed, with the right side, on average, tending to have a smaller diameter than the left side (Table 1).
No significant variationwas observed for the length of the FR $\left(F(1.102)=0.089 ; p=0.767 ; \eta_{p}{ }^{2}=0.001\right)$ or for the length of the FO $\left(\mathrm{F}_{(1.102)}=1.287 ; p=0.259\right.$; $\eta_{\mathrm{p}}{ }^{2}=0.012$ ).

Considering the effect of gender (male, $n=86$; female, $n-18$ ), a statistically significant variation in thewidth of theright FR was observed $\left(\mathrm{F}_{(1.102)}=4.865\right.$; $\left.\mathrm{p}=0.030 ; \eta_{\mathrm{p}}{ }^{2}=0.046\right)$; women had a smaller average diameter than men, and this variation was not observed in the left side (Table 2). No significant variation was observed (Table 2 ) for the length of the FR $\left(F(1.102)=0.089 ; p=0.767 ; \eta_{p}{ }^{2}=0.001\right)$.

Despite the apparent difference in diameter, the length of the $\mathrm{FO}\left(\mathrm{F}_{(1.102)}=0.973 ; p=0.326 ; \eta_{\mathrm{p}}{ }^{2}=0.009\right)$ and thewidth of the FO $\left(\mathrm{F}_{(1,102)}=0.224 ; p=0.637 ; \eta_{\mathrm{p}}{ }^{2}=0.002\right)$ showed no statistically significant variation. 


\section{Discussion}

Trigeminal neuralgia represents an exhaustively describedpathological framework within the neuropathies; however, whenwe investigate the primary causes for this presentation in patients who do not exhibit the classic presentation, the anatomical asymmetry hypothesis cannot be disregarded, ${ }^{8}$ as the etiology of primary TN is unknown..$^{10}$

The asymmetry of the FR and of the FO is recognized by several authors, and variations in their dimensions can be explained by the embryogenesis of the middle fossa-from the presphenoid and basal-sphenoid segments of the developing sphenoid1, ${ }^{9,19}$-given the ossification of the cartilaginous ring that surrounds the nerve root and the other structures that interact with this ring. ${ }^{6,20}$

Our results show a statistically significant difference ( $p=0.011)$ in the morphometry of the left and right sides of the FR and of the FO, $8,10,21-23$ revealing a tendency to present a more narrow format for both the FO and the FR.

Onemust consider the variations relating to ethnic factors and different population groups. Studies of different populations reveal significant and nonsignificant morphometric variations in the same analyses.

The size of the FO in skull samples of a Greek population displayed a mean length and width of $7.2 \pm$ $1.2 \mathrm{~mm}$ and $3.9 \pm 0.7 \mathrm{~mm}$ on the right side, respectively, and a mean length and width of $7.0 \pm 1.1 \mathrm{~mm}$ and $4.1 \pm 0.8 \mathrm{~mm}$ on the left side, respectively - thus showing significant asymmetry. ${ }^{8}$ However, the same measurements in samples of an Indian population showed an average length and width of $7.0 \pm 2.17 \mathrm{~mm}$ and $5.0 \pm 0.42 \mathrm{~mm}$ on the right side, respectively, and an average length and width of $6.8 \pm 1.40 \mathrm{~mm}$ and $4.7 \pm 00.91$ $\mathrm{mm}$ on the left side, respectively, with no significant asymmetry. ${ }^{24}$

Our data show the FO with an average size equal to $6.8 \pm 10.3 \mathrm{~mm}$ in length and $3.3 \pm 0.8 \mathrm{~mm}$ in width for the right side and $6.81 .3 \mathrm{~mm}$ in length and $3.60 .1 \mathrm{~mm}$ in width for the left side, with lower morphometric values than described, however with significant asymmetry $\left(p=0.005 ; \eta_{\mathrm{p}}{ }^{2}=0.075\right)$, according to Natsis et al. ${ }^{8}$

The right-sided FR observed in our samples exhibited a mean length of $2.80 .6 \mathrm{~mm}$ and a mean width of $2.50 .7 \mathrm{~mm}$, and the left-sided FR exhibited a mean lengthof $2.80 .6 \mathrm{~mm}$ and a mean width of $2.50 .6 \mathrm{~mm}$, with a slight trend of significant variation $(p=0.090$; $\left.\eta_{\mathrm{p}}{ }^{2}=0.028\right)$.

Thesemeasurements correspond to those values obtained by Liu et $a l,{ }^{10}$ and were lower than those described by Sondheimer, Berge et al, and Erbagci et al. ${ }^{21,23,25}$

Thus, we can infer that it is not possible to establish astandardized model based exclusively on morphometry for distinct populations, disregarding characteristics of populations and ethnic factors.

Therefore, the shape and size of the foramen may vary within the same ethnic group and between different ethnic groups. Accordingly, each population must be evaluated independently with the prospect of establishingmorphological patterns for the morphometry and asymmetry of the foramina, ${ }^{24}$ as this asymmetry may be related to the pathogenesis of $\mathrm{TN}$.

According to Capel et $a l,{ }^{26}$ the narrowing and lateralizationof the foramen should be considered with caution in theassessment of the pathogenesis of $\mathrm{TN}$, as asymmetry is acommon phenomenon in normal individuals, as reported by Erbagci et al. ${ }^{25}$ Our study shows that, despite the controversial correlation between asymmetry and compression, data concerning the asymmetry cannot be disregarded when attempting to understand the pathogenesis of $\mathrm{TN}^{8}$; recentstudies suggest that the narrowing of the foramen may be etiologically important for a portion of these patients. ${ }^{10}$

Regarding the gender of the individuals, we found a significant asymmetry in the FRs with smaller diameters $\left(p=0.030 ; \eta_{\mathrm{p}}{ }^{2}=0.046\right)$ - smaller on the right side in females - which may explain the greater incidence of right-sided neuralgia reported in the literature. ${ }^{2}$ No significant difference was observed in the asymmetry for males and females with regard to other measurements. According to Murugan et $a l,{ }^{27}$ there was no significant difference in the morphometry of the right and left FOs among male and female individuals.

Taking gender into account, we did not find statistically significant morphometric data to correlate FO asymmetry with the incidence of neuralgia of the V3 branch reported in the literature. This result is comparable to that reported by Murugan et al, in which no significant difference was observed in the left and right FO morphometry between male and female individuals. ${ }^{27}$

Nevertheless, TN affecting the right maxillary branch is thought to be related to a narrowing of the FR in females, as Liu et al described a correlation between the narrowing of this foramen and $\mathrm{TN}^{10}$ The V2 branch is affected in $\sim 39 \%$ of reported cases, ${ }^{2}$ thus establishing a possible correlation between the morphology of the foramen and compression.

\section{Conclusion}

The present study demonstrated that there is asymmetry between the right and left sides of the skull within the population studied, and that the foramina on the right side are significantly smaller than on the left. However, when correlated to gender, this variation 
is significant only for the right-sided FR of female skulls; they were smaller than those on the left side, which could explain the compressive neuropathy of the $\mathrm{V} 2$ root of the trigeminal nerve observed in female patients.
The establishment of a model for standardization based on the morphometry of the FR and of the FO in distinct populations should take into account variables such as gender and ethnic factors, and it may further facilitate our understanding of the pathogenesis of $\mathrm{TN}$.

\section{References}

1. Love S, Coakham HB. Trigeminal neuralgia: pathology and pathogenesis. Brain 2001;124(Pt 12):2347-2360.

2. Bangash TH. Trigeminal neuralgia: frequency of occurrence in different nerve branches. Anesth Pain Med 2011;1(02):70-72.

3. Kitt CA, Gruber K, Davis M, Woolf CJ, Levine JD. Trigeminal neuralgia: opportunities for research and treatment. Pain 2000;85(1-2):3-7.

4. Chakravarthi PS, Ghanta R, Kattimani V. Microvascular decompression treatment for trigeminal neuralgia. J Craniofac Surg 2011;22(03):894-898.

5. Matsushima T, Huynh-Le $P$, Miyazono M. Trigeminal neuralgia caused by venous compression. Neurosurgery 2004;55(02): 334-337, discussion 338-339.

6. Penman J. Trigeminal neuralgia. In: Vinken PJ, Bruyn GW. Handbook of Clinical Neurology. Amsterdam: North-Holland Publ. Co.; 1968:236-332 7. Katusic S, Beard CM, Bergstralh E, Kurland LT. Incidence and clinical features of trigeminal neuralgia, Rochester, Minnesota, 1945-1984. Ann Neurol 1990;27(01):89-95.

8. Natsis K, Repousi E, Sofidis G, Piagkou M. The osseous structures in the infratemporal fossa: foramen ovale, bony spurs, ossified ligaments and their contribution to the trigeminal neuralgia. Acta Neurochir (Wien) 2015;157(01):101-103.

9. NetoHS, Camilli JA, Marques MJ. Trigeminal neuralgia is caused by maxillary and mandibular nerve entrapment: greater incidence of right-sided facial symptoms is due to the foramen rotundum and foramen ovale being narrower on the right side of the cranium. Med Hypotheses 2005;65(06):1179-1182.

10. Liu P, Zhong W, Liao C, Liu M, Zhang W. Narrow foramen ovale and rotundum: a role in the etiology of trigeminal neuralgia. J Craniofac Surg 2016;27(08):2168-2170.

11. Pitres A, Testut L. Les Nerfs em Schémas. Paris: Librairie Octave Doin; 101-1061925.

12. Wilson-Pauwels L, Akesson EJ, Stewart PA. Cranial Nerves. Toronto: BC Decker; 1988:49-55.

13. Schünke M, Schulte E, Schumacher U. Prometheus Lern Atlas der Anatomie: Kopf und Neuroanatomie. Stuttgart: George Thieme Verlag; 2009:74-77.

14. Khairnar KB, Bhusari PA. An anatomical study on the foramen ovale and the foramen spinosum. J Clin Diagn Res 2013;7(03): 427-429 15. White TD, Folkens PA. The Human Bone Manual. Amsterdam: Elsevier; 2005:387-392.

16. Field A. Descobrindo a estatística usando o SPSS. 2a Edição. Porto Alegre: Artmed Editora; 2009:441-473.

17. Marôco J. Análise Estatística com SPSS Statistics. 5a Edição. Pero Pinheiro Report Number. 42-462011.

18. Dancey $\mathrm{CP}$, Reidy J. Estatística sem Matemática para Psicologia. 5a Edição. Porto Alegre: Penso; 2013:123-124.

19. Testut L, Latarjet A. Tratado de Anatomia Humana - Tomo 1. Barcelona: Salvat; 1959:208.

20. James TM, Presley R, Steel FLD. The foramen ovale and sphenoidal angle in man. Anat Embryol (Berl) 1980;160(01):93-104

21. Sondheimer FK In: Newton TH, Potts DG, eds. Radiology the skull and brain: basal foramina and canals. St. Louis: Mosby; 1970: 287308.

22 Jain KK, Jain BK. Asymmetry in the skull. Acta Anat (Basel) 1979; 104(03):349-352.

23. Berge JK, Bergman RA. Variations in size and in symmetry of foramina of the human skull. Clin Anat 2001;14(06):406-413

24. Patil J, Kumar N, KGMR, et al. The foramen ovalemorphometry of sphenoid bone in South Indian population. J Clin Diagn Res 2013;7 (12):2668-2670.

25. Erbagci H, Kizilkan N, Sirikci A, Yigiter R, AksamogluM. Computed tomography based measurement of the dimensions of foramen ovale and rotundum in trigeminal neuralgia. Neurosciences (Riyadh) 2010;15(02):101-104.

26. Capel C, Peltier J. Trigeminal neuralgia: frequency of occurrence in different nerve branches. Anesth Pain Med 2012;1(03):214-215.

27. Murugan M, Saheb SH. Morphometric and morphological study on foramen ovale. Int J Anat Res 2014;2:664-667.
Received: January 30, 2019

Accepted: September 16, 2019
Corresponding author

Marcus Alexandre Mendes Luz

Email: anatomia.fcm@gmail.com 